Grand Valley State University

ScholarWorks@GVSU

$1-2007$

\title{
Contextual Empowerment: The Impact of Health Brigade Involvement on the Women of Miraflor, Nicaragua
}

Gayla Jewell

Grand Valley State University

Follow this and additional works at: https://scholarworks.gvsu.edu/kcon_articles

\section{ScholarWorks Citation}

Jewell, Gayla, "Contextual Empowerment: The Impact of Health Brigade Involvement on the Women of Miraflor, Nicaragua" (2007). Peer Reviewed Articles. 15.

https://scholarworks.gvsu.edu/kcon_articles/15

This Article is brought to you for free and open access by the Kirkhof College of Nursing at ScholarWorks@GVSU. It has been accepted for inclusion in Peer Reviewed Articles by an authorized administrator of ScholarWorks@GVSU.

For more information, please contact scholarworks@gvsu.edu. 


\section{Contextual Empowerment: The Impact of Health Brigade Involvement on the Women of Miraflor, Nicaragua}

\author{
GAYLA JEWELL, PhD, RNC, NP \\ Grand Valley State University
}

\section{BACKGROUND}

Nicaragua is the largest country in Central America, covering an area slightly smaller than the state of New York. The land suffers from significant deforestation, soil erosion, and water pollution. Nicaragua is one of the hemisphere's poorest countries with a per capita income of less than $\$ 500$ per year, flagging socioeconomic indicators, and huge external debt. More than half of the population lives below the poverty line. Unemployment is estimated to be between $11 \%$ and $24 \%$, with another $36 \%$ underemployed. Almost half of the population of Nicaragua works in agriculture. The rural community of Miraflor lays in 200 square miles of mountainous land, northwest of Managua, the nation's capital. Its citizens are mostly of Spanish and indigenous Indian descent. Its demographics resemble those of the country as a whole.

In 1998, Hurricane Mitch pummeled the western region of Latin America, killing more than 10,000 people, laying waste to much of the land, and leaving 1.5 million people homeless (Lonely Planet, 2004). Like many communities, Miraflor was badly damaged. The fragile, limited infrastructure of the country was unable to cope with the devastation. One small effort to provide relief was the organization of Health Brigades in January and March 1999. Funded by a local Grand Rapids, Michigan church and staffed by 6 KCON faculty, 1 staff (interpreter), and 20 students, the Brigades traveled to Miraflor to provide primary health care and health promotion services for 6 clinical days. Approximately 2,000 Miraflor residents were treated during each Brigade.

Author's Note: The author gratefully acknowledges the coresearchers for their vital contributions: Major Nancy Steele, RNC, NP, PhD, Deputy Director OB/GYN Nursing Program, Tripler Army Medical Center, Honolulu, Hawaii; Suzanna Leclaire, RN, MHS, MSN, ENT Care Manager Nurse, Tripler Army Medical Center, Honolulu, Hawaii; Lynn Grass, RNC, NP, MSN, Nurse Practitioner to East Aleutian Tribes, Alaska; and Brenda Pawl, RNC, NP, MSN, Independent Nurse Practitioner, Grand Rapids, Michigan. And a special thanks to Kimberly F. Hartman, BSN, RN, Graduate Assistant (KCON graduate student), for her concerted work on this manuscript with the author. Correspondence concerning this article should be addressed to Gayla Jewell, Kirkhof College of Nursing, Grand Valley State University, Grand Rapids, Michigan 49503; e-mail: jewell@gvsu.edu. 
Following the March 1999 trip, the two lead investigators met with Miraflor community leaders to investigate the potential for an ongoing partnership. With significant support from the Nicaragua Ministry of Health (MINSA), an agreement was struck for semi-annual Health Brigades to provide six 12-hour clinical days per visit. Health Brigades continued from October 1999 through February 2003, for a total of 10 visits. It was during the last Brigade in February 2003 when study data was collected. The Brigades were staffed by KCON faculty and students and organized by the Miraflor community leadership. From 2001 through 2003, each Brigade was augmented by four students from La Trinidad School of Nursing and two faculty from the Medical School of Leon, both departments within the Autonomous University of Nicaragua (UNAN). These students and faculty provided critical information and assistance for the provision of culturally appropriate care. The authors respectfully acknowledge the contributions of the Nicaragua partners to the work and impact of the Brigades. However, it is difficult to determine the level of their influence on the women's sense of empowerment.

\section{MIRAFLOR EXPERIENCE CONSISTENT WITH INTERNATIONAL AGENDA}

Inequity is a sad reality throughout the world. For several decades, international organizations have created public statements about the need to work toward equity and universal human rights. This began with the Universal Declaration of Human Rights, created in 1948 by the General Assembly of the United Nations (UN), and has continued in summits such as the UN Human Rights Conference in Vienna in1993, the Cairo Consensus in 1994, and the Fourth Conference on Women in Beijing in 1995. During the debates that led to these and other declarations, the argument was made that, rather than economic development being the main goal, human development should be the primary and direct objective of economic growth (Walpole, 1996). This argument shifted the perspective from one of economics to that of linking human rights with development. Inherent in this perspective are the rights of women and issues related to gender-power relations, which encompass other power inequities emerging from classism, racism, ageism, and so forth. When power inequities exist, it is too often the women who are unempowered.

The UN Human Development Report describes women as essential agents of political and economic change and affirms the fundamental value of investing in women's capabilities and choices as the most effective contribution to economic growth and overall development (Walpole, 1996). Sadly, much of the work that women do in Miraflor and throughout the world is rendered invisible because it involves daily chores and is not valued as paid labor. This invisibility of women's work feeds into a sense of unimportance, decreased value and self-efficacy, and disempowerment (Doyal, 1995; Erlich \& King, 1998; MacKinnon, 1989).

The investigators were aware that empowerment and gender equity had been established as strategic objectives for sustainable, people-centered development by the Development Action Committee of the UN in 1996 (Organisation for Economic Cooperation and Development [OECD], 1998) and various other summits. By 2000, the OECD and the UN had joined forces to identify a strategic plan "to achieve just and equitable societies where the contributions of women are placed center stage" ("Empowering Women," 2000). This trend reflected recognition of the emergence of women's voices in socially conscious leadership (Wagner \& Cook, 1999). Therefore, incorporation of gender empowerment into the Health Brigade outcomes, although not anticipated, was consistent with the international organizations' agendas. It was with slowly growing awareness that the research team realized that the women of Miraflor and their conscious efforts toward empowerment were a microcosm of the international agenda.

\section{CONCEPTIONS OF EMPOWERMENT}

Empowerment is a complex phenomenon that holds many dimensions and elements within itself. Dimensions include those directed to the individual, among individuals, and to the community/society. The work of Carl Rogers and the human potential movement of the 1950s and 1960s emphasized the power of individual persons. Thomas and Velthouse (1990) conceptualized empowerment as including self-efficacy (competence), self-determination, and impact. Bush and Folger (1994) offered similar elements in their definition: "Empowerment means the restoration to individuals of a sense of their own value and strength and their own capacity to handle life's problems" (p. 12).

Conger and Kanugo (1988) described empowerment as a relational concept (i.e., concerned with the redistribution of resources and power). In a similar vein, Gibson (1991) described empowerment as a transactional process-a dynamic, reciprocal process during which each party in the interactional experience is more able to do what they need to do. Wallerstein and Bernstein (1988) proposed that empowerment involves the individual's increasing self-efficacy as well as environmental change. Likewise, linking the individual agency with a more sociological perspective, Rissel (1994) referred to two dimensions: psychological empowerment (an increased sense of self-determination) and community empowerment (political actions with active participation and redistribution of resources or decision-making that is of benefit to the community).

Kanter (1977) purported that empowerment is a process that includes the context of the situation as well as what the individual brings to it. This perspective rings true with Rappaport's (1984) notion that empowerment eludes a 
single definition because it needs to be defined by the people concerned. Empowerment takes on a different form in different people and within different contexts. Therefore, empowerment is a synergistic paradigm (Katz, 1984) of mutually beneficial interactions that strengthen the individuals and the community within the sociological context of that community.

The investigators contend that empowerment plays a crucial role in personal and community development and maintenance. Empowerment refers to a sense of agency or self-efficacy (competence) as well as shared power in the community and decision-making processes. In addition, empowerment is a positive concept that focuses more on solutions than problems. It is an interrelational process that occurs within the complex political, cultural, social, and economic forces that impact people's lives.

\section{THE WOMEN OF MIRAFLOR AND THE HEALTH BRIGADES}

Initially, only the men of Miraflor participated in planning and evaluating the Health Brigades. Women tended to stand just outside the door of the room in which the meetings took place. During the course of 1 to 2 years, women began to quietly enter the room to listen. As time passed, they joined in the meetings and began to comment on food purchase and preparation. They were aware when diarrhea became a problem for the nursing students and faculty during the Brigade trips and identified preventive strategies. These women began to realize and value their own contributions to the community as unique and important.

Early in 2002, the lead investigators compared their observations about the increasing involvement of many Miraflor women in the Brigades project, noting that they seemed to be taking on more responsibility and authority. It was this change in behavior that led the investigators to embark on a qualitative investigation of this evolving, gender-power phenomenon. From the investigators' perspective, it seemed that the Miraflor women were becoming empowered to speak out and take a more active role in planning, implementing, and evaluating the Health Brigades with a resultant shifting of individual and community power that was changing gender-power relations. The research question of interest became: Do the women of Miraflor demonstrate a heightened sense of empowerment as a result of working with the Health Brigades?

\section{HISTORICAL CONTEXT OF LACK OF EMPOWERMENT}

This investigation of empowerment began with understanding the historical context of power in the Miraflor community to provide grounding for the theoretical concepts. Gender-power inequity is based, in part, in the historical social-cultural relations of machismo. Machismo is a man's sense of entitlement to power over women and lesser men; it is a dominant wielding of power over the marginalized ("Machismo in Latin America," 1999). Women were oppressed by men as a function of historic social relations. They were not permitted to participate in community leadership and decision making. Men's fear of losing control was an obstacle to women's empowerment. Oppression within the sociocultural context of Miraflor was evident in the lack of women's mobility away from the farm and repression of involvement in family decision making. In addition, women were oppressed by the state of poverty in the country. The following interview comments by the women describe this historical context:

Before, I was scared of my husband. I had to ask for everything.

Before, my father was not involved in any organization or cooperative, and he wouldn't let me leave and participate.

There are couples where the husband still won't let the woman leave the house.

\section{DIFFERENCES, SIMILARITIES, AND NEGOTIATED DEFINITIONS}

Empowerment and gender equality, although seemingly universal concepts, must be carefully considered within community and cultural contexts, which proved true of this study of Miraflor. Six months before the formal interviews for the research project began, the investigators talked with several women who had participated with the Brigades. The question posed was, "What impact has working with the Brigades had on you?" Initial responses indicated that they had made new friends and had found new recipes for their families. The investigators refined the question to ask, "What impact has working with the Brigades had on you personally as an individual?" Again, the women stated that they were building stronger networks among the villages, that they were trading and sharing garden vegetables, and that harmony between the villages had improved because the women were talking together. Finally, the comment of one wise woman struck the investigators. She said,

I know what you are asking... but I can't answer your question. In the U.S. when you say "empowerment," you mean I can do this and I can get ahead. Here in Miraflor when we think of "empowerment," we think, "We can do this." No one takes steps forward without holding the hands of others on either side of them.

With this comment, the investigators realized their own biases about empowerment and gender equality. The U.S. culture-based attitude about individual empowerment and self-capacity to compete and endure was a personal cultural bias about which they were inadequately aware. The Miraflor women redefined empowerment for the investigators as 
being about creativity, confidence, resources, endurance, and working together.

The investigators are citizens of and were educated in the United States, where the dominant assumption is that individuals are endowed with a sense that they can successfully confront challenges. Best described by Bandura (1997) as "self-efficacy" or by others as "self-mastery," this sense of selfempowerment is culturally consistent with ways of addressing life challenges in the United States and Western European cultures (Bandura, 1997; Carver \& Scheier, 1998; Jackson, McKenzie, \& Hobfoll, 2000). In these individualist cultures, the dominant belief is that solving problems and dealing with life challenges is based on one's own effort. In contrast, the women of Miraflor demonstrated characteristics of a more collectivist culture. In this context, problem solving is seen as best done through group effort: by getting along with others and by being interwoven in a close, social network (Hobfoll, Jackson, Hobfoll, Pierce, \& Young, 2002). Although dominant U.S. culture explains success in terms of the individual's attributes, talents, and abilities, Miraflor, a collectivist culture, emphasizes behaviors that promote vital connections among people.

Through this lesson taught by the Miraflor women, empowerment as a theoretical ideal was defined as a process of change that implies alternatives (the ability to have chosen otherwise). It also refers to the expansion in people's ability to make strategic life choices in a context in which this ability was previously denied to them within a collectivist culture.

Despite cultural differences, the investigators and the Miraflor women established relationships and an appreciation of the support provided by their partnership during the course of the Brigades. Although differences were noted and explored, these growing friendships offered opportunities for similarities to be appreciated. The obvious fact was that the investigators and research subjects were all women. Women, no matter where they live, have similar bodily experiences (even though the meanings attached to them may vary dramatically) and experience similar psychosocial and structural constraints (Doyal, 1995). It was in recognizing these similarities that the definition of gender emerged. For the purposes of this research and in the Miraflor context, gender is defined as a social- and cultural-based power relationship that mediates the ways in which people experience psychosocial and structural constraints according to their sex. The difference is centered in how gender-power relationships and empowerment are operationalized in collectivist versus individualist cultures.

\section{TOWARD A GROUNDED THEORY OF CONTEXTUAL EMPOWERMENT}

Grounded theory explores how people define reality and how their beliefs are related to their actions (Burns \& Grove, 1999). Consistent with this approach, theoretical concepts are presented from a "bottom up" perspective (i.e., from the individual to the larger social perspectives). Through qualitative analysis, two theoretical contexts emerged from the data: the psychosocial context and the structural context. Within each context, several dimensions became evident.

In the psychosocial realm, "insider" dimensions are depicted by the two small inner circles on the left side of the model (see Figure 1). These dimensions include empowerment, agency, and self-awareness. This is consistent with Doyal's (1995) psychosocial realm in which women struggle to maintain a sense of self which is considered "other." The structural realm is described as the outsider influences that intersect with the psychosocial contexts. This is depicted by the ring on the right side of the model. These include Nicaragua's national interests (MINSA), the Health Brigades staffed by outsiders from the U.S., and by students and faculty from La Trinidad School of Nursing and the Medical School of Leon-all Nicaraguan citizens, but outsiders to Miraflor.

The intent of the investigators was to use the women's words and stories to create a framework that helped to explain their lived experience as they strengthened their position of contextual empowerment. This framework uses terminology consistent with the U.S. Western perspective to bridge understanding between words spoken by the women of Miraflor and the readers of this article.

\section{RESEARCH DESIGN AND PROCESS}

As an inductive technique consistent with grounded theory, this qualitative research is rooted in the data from which it was derived. The researchers chose to look to the Miraflor women as the data source for the grounded theory to explain their experience of empowerment (i.e., to provide the data for an empirical and local-level analysis). Permission to formalize the research process was obtained from the Human Subjects' Review Board at GVSU. Purposeful, convenience sampling was used. Any woman who was a resident of Miraflor between the ages of 18 and 65 years and who had worked with the Health Brigades at any time was invited to be interviewed. A total of 10 women were interviewed: 2 were aged 19 to 30 years, 5 were aged 31 to 45 years, 2 were aged 46 to 65 years, and 1 participant's age was unrecorded. Although a direct question about marital status was not included, information regarding the woman's role or position in the family was obtained.

The informed consent form was translated from English to Spanish and back again to English for validation. Data were collected by means of a structured-interview format with open-ended prompts. The interviewers were two KCON graduate nursing students who were new to the Brigades. In this way, the principal investigators' biases were minimized. The interview questions were verbally translated into Spanish for the women by an indigenous interpreter. The women's responses were immediately translated into written 


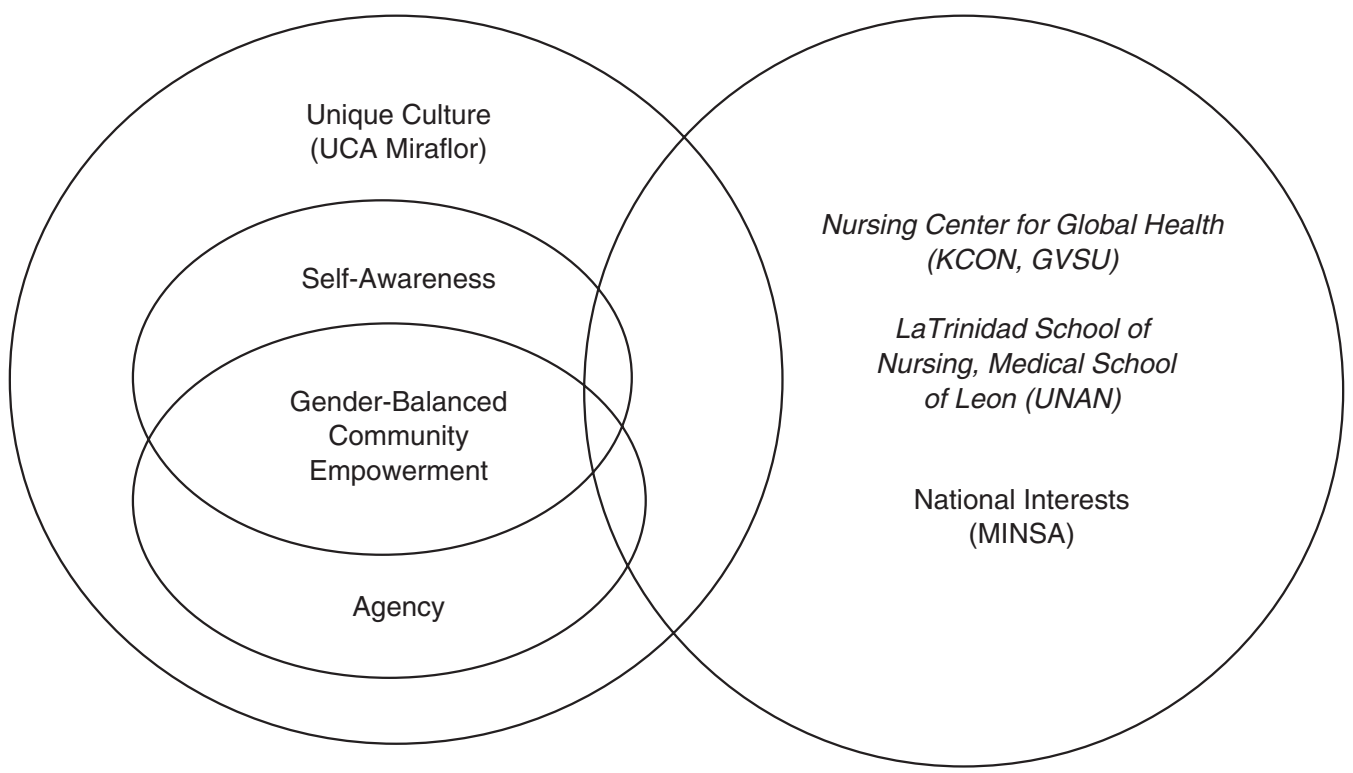

FIGURE 1. Toward a Grounded Theory of Contextual Empowerment.

English by the research assistant whose first language is English and who is also fluent in Spanish. Literal translation was recorded by hand by the bilingual research assistant, then verbal interpretation was sought with the interviewed woman to ensure richness of text. Each interview averaged about 1 hour in length. Transcription was verbatim. No audiotapes were used because these were regarded as a barrier to self-expression; the tape recorders were a source of curiosity and distraction. Handwritten interviews were then transcribed and reviewed for reliability.

\section{DATA ANALYSIS}

Copies of all typed transcripts were distributed to the research team (three nursing faculty and two graduate students). Interrater reliability was protected by independent analysis. As an individual effort, each researcher read through the responses a minimum of three times to become immersed in the data. Open coding was used to identify patterns of responses. Next, the data were dissected and categories of relevant relationships and processes identified for later data analysis. Within each category, relationships and processes were uncovered for each woman interviewed. Axial coding was implemented to connect categories found in the open coding process (Polit, Beck, \& Hungler, 2001). Each team member individually wrote her axial memorandum identifying causal conditions observed in the data analysis.

The research team then met to compare findings. Threats to interpretative validity were diminished by literature review and data analysis by all team members. Although the team was pleased with the amount of data collected and found sufficiently repeated themes to validate category formation, saturation was not achieved. The project was moving toward a theoretical sampling for the older women but had insufficient data sampling for the younger women.

After core categories were identified through selective coding, a matrix of theoretical concepts was completed. Consequently, these theoretical concepts were used to create a more detailed matrix of the phenomena under study. The matrix was synthesized into a grounded theory model based on the lived experience of the interviewed Miraflor woman. This model describes the psychosocial and structural dimensions of the data.

\section{INTEGRATED FINDINGS}

\section{The Psychosocial Realm}

The three emergent dimensions of the psychosocial realm of empowerment are self-awareness, agency, and community empowerment. The process of self-awareness includes (a) awareness of historical machismo, (b) awareness of one's own interests, and (c) awareness of how one's interests relate to others. The following interview comments illustrate self-awareness:

Now I learned that I need to ask about even things like,

"Have you been faithful?" I found my voice.

They [Health Brigades] helped me mature. I'm not the child hiding behind the door now. I talk to people.

You [Health Brigade members] come here to show friendship and solidarity. You are a great example to us. 
Enacted self-awareness with its companion sense of selfconfidence grew into a sense of agency. Agency is defined as feeling capable to take action, such as participating from a position of strength in decision making and action. Agency reflects a process by which the women move from unquestioning, complicit, or coerced acceptance of the social order to a critical perspective of it. First, women had to realize the possibility of choice, then act on it. Comments by the women that describe agency include the following:

Now I feel like I have the capacity to do these things. I feel capable to support and to provide support for the family and can relate to other people.

I speak for the family in public.

We speak together.

I am a Mari-Macho: a woman acting like a man!

I am the door-keeper [during the Brigades]. They need a person with lots of authority. They respect me.

You can see it with your own eyes-here! The men are at home and I am here!

This agency caused a change not only in the women who worked with the Brigades; it also caused a transition in the way in which the Miraflor women and men related to each other. This transition in relationships was experienced as a sense of gender-balanced community empowerment, which occurred within the context of the unique culture of Miraflor. Community empowerment is a relationship concept that was found to mean harmony in mutual respect and effort. The women described this as follows:

There was a lot of machismo-we learned that we have equal rights.

There is decreasing domestic violence toward women and children.

It's like a coordination-like looking for equality between men and women.

Now we are not shy anymore- even about our bodies. We work in a group.

Note the persistent use of "we" as opposed to "I." This implies that the individual woman is not seen as the source of her own success. Instead, successful empowerment seems to occur through sustained attachments among community members on two levels: (a) Women as a group and women and men as a group succeed by working together, and (b) having others to work with is a reflection of success (Hobfoll et al, 2002).

\section{The Structural Realm}

Dimensions of the more over-arching structural realm include the local culture constrained by poverty, Nicaragua's national interests (including MINSA), and external partnerships. Local culture includes the historical machismo attitude, rigid gender roles, and how value is placed on women's work. Local culture was described by the women as follows:

Men used to work apart; they thought that women could not do the work. We work equally now.

Now the men help in the house. Now the men let the women go to the meetings.

The Nicaragua constitution provides for equal rights and health care, but severely limited resources, governmental corruption, and persistent cultural attitudes create barriers to the activation of these rights. Therefore, the national interests include the dilemma of needing to provide adequate health care and employment, but having restricted or misallocated resources to do so. Women described this dilemma as follows:

Having the Brigades here does not mean money for referrals and surgery.

The people here are poor. They die from diarrhea. They don't go to the city to get care.

We have a very high cervical cancer rate-over 30\%. A lot of women die.

External partnerships, also defined as outsider influence, include the presence of La Trinidad School of Nursing students, Medical School of Leon faculty, and the KCON Brigade members. Some of the outsider influence effect was planned; for example, the Brigades provided supportive health services, and the Miraflor women provided supportive living services to the Brigade members. Other influences were unplanned, for example, observation of female and male brigade members working and living in close proximity affected Miraflor women's attitudes about the sexes working together. The following describes the influence that this had:

The Health Brigades have been examples for us-modelsthey make us strong.

The Brigade members work together, sleep together, and, in contrast, here, before, a woman could not even talk to a man for jealousy of her husband.

It is important that the women know about the Brigade and share experiences. The Brigade helps the people and the women help the Brigade.

\section{DISCUSSION}

This derived, grounded theoretical model is a simple window to one point in time, framing the complex process of change in the Miraflor community. The model shows distinguishable and connected realms of self-perceptions, relations, and processes in a particular context. This reveals that empowerment is not simply a matter of choice. It is embedded in the 
women's sense of self-awareness and agency as connected with the community's sense of empowerment and in the wider contexts created by the culture, national interests, and outsider involvement. The dimensions of the theoretical model for contextual empowerment are indivisible; they cannot be measured independently.

The model's dimensions are not a measurement of the women's abilities to make choices. Rather, it indicates the direction and meaning of the change being observed. The model highlights the women's perceptions of value in their movement and, thereby, the community's movement toward empowerment within their own cultural context. It reveals mutually reinforcing effects of the dimensions of power in the contextual empowerment process.

The movement toward or away from contextual empowerment is a social practice embedded in a particular set of social relations that, in turn, produces a series of variable and interlocking gender-power inequity constraints that can inhibit lives or become a space for agency. It is these constraints that are identified in the women's interviews. The researchers identified that the women are engaged in a conscious effort to step away from the social and cultural constraints to create an alternative and more power-balanced social method that lays the foundation for constructive change and community growth. This contextual empowerment of the women and, thereby also the men and the community, could provide a stronger foundation for more sustainable economic development and partnership methods to meet the health needs of the people of Miraflor.

\section{Limitations}

One result of the wise teachings of the women of Miraflor was that all five researchers admitted to personal and professional cultural biases. Indeed, all members from the 5 years of Health Brigades, whether consciously or not, demonstrated cultural biases. Some of the biases were identified early and dealt with, as previously indicated. Others remain unidentified, and their influence on the research process remains unknown. It is also possible that the research project includes participant response biases; the women may have desired to please the researchers and responded in their interviews accordingly.

Caution in data interpretation is also needed because of language and cultural differences. As previously described, although effort was made to accurately and sensitively translate and interpret from English to Spanish and back again, challenges did exist. Local dialect, vocabulary, and nonverbal communications were a challenge for the interpreter who lived only 20 kilometers from Miraflor. Attempts were made, as previously described, to thwart this limitation; however, the language and cultural differences remain a limitation of the study (LoBiondo-Wood \& Haber, 2002).

Even though the research topic was about the impact of working with the Health Brigades on the women of Miraflor (and only those women were interviewed), it may have provided additional perspective to interview the men. Empowerment is a relationship-based process through which the perceptions, values, and interactions of women and men change. Gender-power relations cannot transition for the better unless men are involved (i.e., the nature of men's participation in gender inequities and their effort in working with the women must be analyzed within their own context). Therefore, the inclusion of men in the interview process could enrich findings and recommendations.

Finally, this theoretical model cannot be generalized. The researchers do not presume to identify a single model of change. Identification of a such a model of empowerment would negate the concept and process of contextual empowerment - the women's capacity for self-determination within the context of their lives and their community. The intent of the researchers was to respect and promote the space in which the women could identify and define their own priorities and make their own choices (Hunt, 1996; Rowlands, 1997). It was not to create a grand theory, but to describe a grounded theory, embedded in the lived experience of the women of Miraflor.

\section{Implications for Nursing and Future Research}

One vital implication is for nurse researchers to develop awareness of their own ethnocentrism and how their use of words, language, and value-laden concepts can bias their practice and research. The investigators' initial conception of empowerment is an example of such ethnocentrism.

To avoid these pitfalls, nurses are encouraged to develop awareness of their own impact when establishing and participating in projects such as this in other cultures. Nursing assessment of an individual's or a community's health needs are best balanced with the opinion and lived experience of the local community. Undertaken with knowledge of the limited community resources and dependence on external resources for health services and funding, local populations must define their own problems and articulate possible solutions in negotiated sessions with the researchers and/or outsider influences.

The partnerships that result from action taken in this context of knowledge and respectful negotiation must be sincerely respected by ongoing commitment. Nurses and nurse researchers must be careful of the shallow experience and momentary hope created by transient relationships based on outsider influence. Partnerships must be continually negotiated to promote respect and commitment for the priority partner: the community. What can be misleading is that, too often, projects are regarded as self-limited—lasting maybe 3 to 5 years. But when the processes of empowerment involve women themselves delineating the issues and managing the individual and community transitions, many years may be needed to embed and solidify the changes. (This also offers the opportunity for longitudinal studies for the nurse researchers.) 
Long-term, negotiated partnerships can serve to energize (contextually empower) local communities to begin the slow and tedious process of leveraging their resources, taking charge of their health problems, and, eventually and ideally, limiting their dependence on external assistance. In addition, they can serve to empower all partners through the shared experiences and ever-growing knowledge about the many ways people can live and work together. In the case of Miraflor, some level of dependence on the partnership will persist because the high level of poverty in Nicaragua as a developing nation.

Future research to further develop this model of contextual empowerment could involve at least two issues: (a) Greater care would be needed in selecting and quantifying the concepts that are to serve as indicators of empowerment, with attention to significant stages of decision-making processes as well as the innate senses of self-awareness, agency, and connectedness for women, men, and the community; and (b) greater care would be needed to identify how involvement and participation in decision making impacts actual strategies for change. The experience of women sitting at the cooperative board-meeting table may give the illusion of respectful involvement. However, clearly defined measures of the outcomes of gender empowerment efforts are the real proof. The need to understand the dynamics of empowerment, including the empowerment of women, is vital to promoting equity among individuals and between women and men at the community level, nationally, and from the global perspective.

\section{CONCLUSION}

This qualitative research describes the life experiences of the Miraflor women in relationship to the Health Brigades and their home communities and how the grounded theory of contextual empowerment was created. It is the investigators' hope that this research also documents the meaning of the women's experiences. For the nursing profession and future research, this project serves as a model for engagement with another culture and a way to be more conscious of, and to evaluate some outcomes of, that engagement.

\section{REFERENCES}

Bandura, A. (1997). Self-efficacy: The exercise of control. New York: Freeman. Burns, N., \& Grove, S. K. (1999). Understanding nursing research. Philadelphia: W. B. Saunders.

Bush, R. A. B., \& Folger, J. P. (1994). The promise of mediation: Responding to conflict through empowerment and recognition. San Francisco: Jossey-Bass.

Carver, C. S., \& Scheier, M. F. (1998). On the self-regulation of behavior. New York: Cambridge University Press.

Conger, J. A., \& Kanugo, R. N. (1988). The empowerment process, integrating theory and practice. Academy of Management Review, 13, 471-482.

Doyal, L. (1995). What makes women sick: Gender and the political economy of health. New Brunswick, NJ: Rutgers University Press.

Empowering women. (2000). The OECD Observer, 220, 60-61.
Erlich, S., \& King, R. (1998). Gender-based language reform and the social construction of meaning. In D. Cameron (Ed.), The feminist critique of language (2nd ed., pp. 164-179). London: Routledge.

Gibson, C. H. (1991). A concept analysis of empowerment. Journal of Advanced Nursing, 16, 354-361.

Hobfoll, S. E., Jackson, A., Hobfoll, I., Pierce, C. A., \& Young, S. (2002). The impact of communal mastery on emotional outcomes during stressful conditions: A prospective study of Native American women. American Journal of Community Psychology, 30(6), 853-871.

Hunt, J. (1996). Situating women's development needs within the human rights framework. In G. Moon (Ed.), Making her rights a reality: Women's human rights and development (pp. 24-34). Victoria, Australia: Community Aid Abroad (member of Oxfam International).

Jackson, T., McKenzie, J., \& Hobfoll, S. E. (2000). Community aspects of self-regulation. In M. Boekaerts, P. R. Pintrich, \& M. Zeidner (Eds.), Handbook of self-regulation (pp. 275-300). San Diego, CA: Academic Press.

Kanter, R. M. (1977). Men and women of the corporation. New York: Basic Books.

Katz, R. (1984). Citizen empowerment: A developmental perspective. Prevention in Human Services, 3, 201-226.

LoBiondo-Wood, G., \& Haber, J. (2002). Nursing research: Methods, critical appraisal, and utilization. St. Louis, MO: C.V. Mosby.

Lonely Planet. (2004). Worldguide: Nicaragua. Retrieved November 18, 2004, from http://www.lonelyplanet.com/destinations/central_america/nicaragua/

Machismo in Latin America. (1999). Retrieved June 25, 2004, from the Zona Latina Web site: http://www.zonalatina.com/Zldata77.htm

MacKinnon, C. (1989). Toward a feminist theory of the state. Cambridge, MA: Harvard University Press.

Organisation for Economic Cooperation and Development. (1998). DAC guidelines on gender equality and women's empowerment in development cooperation. Retrieved June 30, 2003, from http://www.oecd.org/ dataoecd/56/46/28313843.pdf

Polit, D. F., Beck, C. T., \& Hungler, B. P. (2001). Essentials of nursing research: Methods, appraisal, and utilization. New York: J. B. Lippincott.

Rappaport, J. (1984). Studies in empowerment: Introduction to the issue. Prevention in Human Services, 3, 1-7.

Rissel, C. (1994). Empowerment: The holy grail of health promotion. Health Promotion International, 9, 39-47.

Rowlands, J. (1997). Questioning empowerment: Working with women in Honduras. Oxford, UK: Oxfam.

Thomas, K. W., \& Velthouse, B. S. (1990). Cognitive elements of empowerment: An "interpretive" model of intrinsic task motivation. Academy of Management Review, 15(4), 666-681.

Wagner, H. T., \& Cook, A. S. (1999). Enhancing the economic contributions of international women through education and training. International Education, 29(1), 71-82.

Wallerstein, N., \& Bernstein, E. (1988). Empowerment education: Freire's ideas adapted to health education. Health Education Quarterly, 15(4), 379-394

Walpole, S. (1996). Welcome. In G. Moon (Ed.), Making her rights a reality: Women's human rights and development (pp. 13-14). Victoria, Australia: Community Aid Abroad.

Gayla Jewell, PhD, RNC, NP, is on faculty at the Kirkhof College of Nursing and coordinates the Interdisciplinary Nicaragua Initiative. She teaches assessment and diagnostic reasoning, primary health, women's health, and various foundation courses at the undergraduate and graduate levels and has held faculty-practice positions. She obtained her BSN from West Virginia Wesleyan College, her MSN from Ohio State University, and PhD study in sociology from Michigan State University. Research interests include interorganizational collaboration, prostituted women's issues, cross-cultural issues, and the impact of international programming on receiving communities. She is NCC certified as a Women's Health Nurse Practitioner. 